\title{
Erich Regener and the ionisation maximum of the atmosphere
}

\author{
P. Carlson ${ }^{1}$ and A. A. Watson ${ }^{2}$ \\ ${ }^{1} \mathrm{KTH}$ and the Oscar Klein Centre, Stockholm, Sweden \\ ${ }^{2}$ School of Physics and Astronomy, University of Leeds, Leeds, UK \\ Correspondence to: A. A. Watson (a.a.watson@leeds.ac.uk)
}

Received: 4 June 2014 - Revised: 4 November 2014 - Accepted: 10 November 2014 - Published: 18 December 2014

\begin{abstract}
In the 1930s the German physicist Erich Regener (1881-1955) did important work on the measurement of the rate of production of ionisation deep under water and in the atmosphere. Along with one of his students, Georg Pfotzer, he discovered the altitude at which the production of ionisation in the atmosphere reaches a maximum, often, but misleadingly, called the Pfotzer maximum. Regener was one of the first to estimate the energy density of cosmic rays, an estimate that was used by Baade and Zwicky to bolster their postulate that supernovae might be their source. Yet Regener's name is less recognised by present-day cosmic ray physicists than it should be, largely because in 1937 he was forced to take early retirement by the National Socialists as his wife had Jewish ancestors. In this paper we briefly review his work on cosmic rays and recommend an alternative naming of the ionisation maximum. The influence that Regener had on the field through his son, his son-in-law, his grandsons and his students, and through his links with Rutherford's group in Cambridge, is discussed in an appendix. Regener was nominated for the Nobel Prize in Physics by Schrödinger in 1938. He died in 1955 at the age of 73 .
\end{abstract}

\section{Introduction}

Erich Regener was born in West Prussia in 1881. He studied physics at the University of Berlin, and his 1905 thesis (Regener, 1905) concerns the interaction of UV light with oxygen and ozone molecules and the equilibrium between them, a topic that he revisited on several occasions. In Berlin he chose as the subject for his Habilitationsschrift the determination of the elementary electric charge using different methods, including alpha-particle scintillations (Regener, 1911). His accurate determination of $e$ is very close to today's accepted value.

After a period as professor at the Agricultural University of Berlin and as X-ray field technician during the 1914-1918 war, Regener became a full professor of physics at the Technical University of Stuttgart in 1920. A hot topic at this time was the study of atmospheric ionisation following the 1912 discovery of cosmic rays ${ }^{1}$ by Victor Hess (1883-1964), and,

\footnotetext{
${ }^{1}$ Before ca. 1930 "Höhenstralung" and "Ultrastrahlung" were terms often used for what are now known as "cosmic rays".
}

from the second half of the 1920s, Erich Regener made significant contributions to the study of this field, both through work that he carried out himself and through stimulating work carried out by his son and by his students, both with him and independently: some of these activities are related in Appendix A. Regener realised that ionisation measurements had to be made deep in lakes and at the highest altitudes and developed the necessary instruments, along with innovative recording techniques, to make such measurements.

Because his first wife, Viktoria, was a Russian-born Jew Regener had to take "provisional retirement" in 1937 for refusing to divorce her (B. Hoerlin, 2011). While his son and daughter emigrated, Regener started a private research institute on Lake Constance in 1937 that was supported by the Kaiser Wilhelm Society and soon became part of the Society. He was recruited by Wernher von Braun to design instruments for rocket flights that were initially to be used to measure the temperature, pressure and density in the upper atmosphere. After World War II Regener became the first vice president of the Max Planck Gesellschaft (formerly the 
Kaiser Wilhelm Gesellschaft) and was reinstated to the chair in Stuttgart, which he held until his retirement in 1951. In 1952 his private institute was incorporated into the, MaxPlanck-Gesellschaft as the Max-Planck-Institut für Sonnensystemforschung. Regener died in 1955: an obituary written by the Nobel Laureate P. M. S. Blackett appeared in Nature (Blackett, 1959).

\section{Cosmic ray work at Stuttgart}

Regener began his cosmic ray work in Stuttgart in 1928. In that year he noted (Regener, 1928) that the study of the "Hess radiation" is difficult for several reasons: the instrument can contain radioactive material, the air can contain radioactive emanations and the ground contains radioactive radium. Any instrumental radioactivity can be investigated by measuring the ionisation in deep lakes, while measurements at high altitudes avoid the ground radioactivity.

Regener was an ingenious experimentalist and soon established a depth record for observations of the rate of production of ion pairs. He tackled the problem of measuring the decrease in ionisation as a function of increasing depth by submerging a quartz-fibre electrometer and a pressure chamber in the waters of Lake Constance. He succeeded (Regener, 1933a) in measuring the rate of ionisation (pairs of ions produced $\mathrm{cm}^{-3} \mathrm{~s}^{-1}$ ) down to a depth of $231 \mathrm{~m}$, where the rate was found to be very low and of the order 0.05 ion pairs $\mathrm{cm}^{-3} \mathrm{~s}^{-1}$. Millikan and Cameron (1928a), working in the US, reached a depth of $50 \mathrm{~m}$, where the ionisation was about 2.6 ion pairs $\mathrm{cm}^{-3} \mathrm{~s}^{-1}$. The "steel bomb" in which Regener measured the ionisation weighed $130 \mathrm{~kg}$ and contained $\mathrm{CO}_{2}$ at a pressure of 30 atmospheres. His early work, carried out using a hand-operated winch on a rowing boat, was so successful that it attracted sufficient funding to purchase a motor boat for later work. He named this boat "Undala", reflecting his belief, and one that was widely held at that time, that cosmic rays were photons with wavelike properties rather than particles. Interesting accounts of the underwater research have been given by Paetzold et al. (1974) and by Pfotzer (1985). Pfotzer worked with Regener, first as a student from 1929 and later, after the war, as a senior scientist.

Regener's work in Lake Constance (Regener, 1931) was highly regarded by eminent physicists of the day, including Bruno Rossi (1905-1993), a close friend despite their differing views on the nature of cosmic radiation (Rossi, 1985). At the Royal Society discussion meeting of 1931 (Geiger et al., 1931), attended by the likes of Geiger, Rutherford, Wilson and Bragg, both Geiger and Rutherford praised Regener's work although they disagreed as to whether it provided evidence for the particle (Geiger) or wave (Rutherford) nature of the radiation. In Rossi's 1985 article there is a photograph of Rossi with Lise Meitner - also a supporter of the wave hypothesis - and Erich Regener (two of Rossi's “dearest

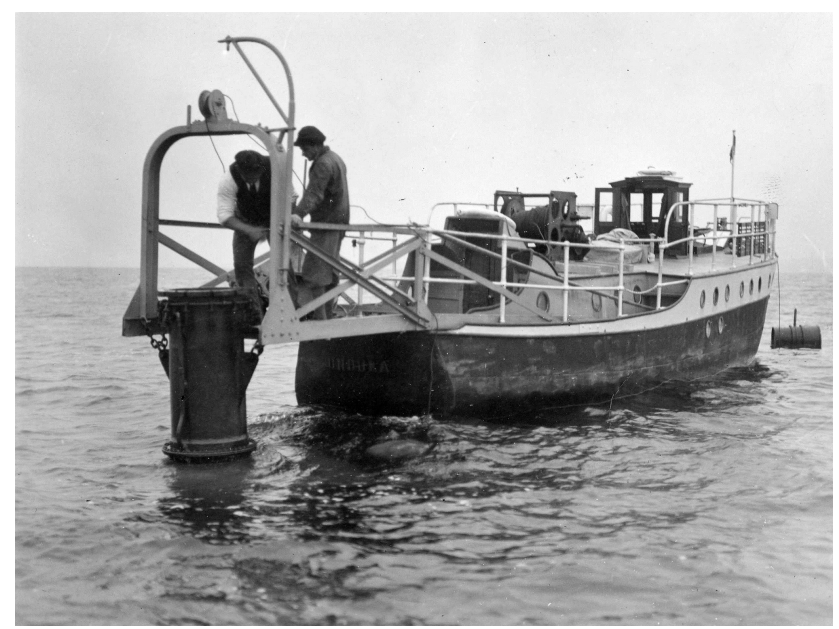

Figure 1. Erich Regener, on the left, on board the Undula on Lake Constance $\sim 1933$. Credit: Archiv der Max-Planck-Gesellschaft, Berlin-Dahlem.

and most respected friends") aboard Regener's boat on Lake Constance. Part of the caption reads "Regener had baptized the boat "Undula" to reaffirm his faith in the wave nature of cosmic rays. Here, following a discussion on this subject, he was telling me: "If it turns out that you are right, I would have to rename my boat "Korpuskel", which does not sound as nice as "Undula"."' No date is given for this photograph, but it was presumably taken in the early 1930s and before the discovery of the East-West effect that did much to establish the particulate nature of the radiation (Johnson, 1933; Alvarez and Compton, 1933). A photograph of Regener working aboard the Undula is shown in Fig. 1.

In the early 1930s Regener started a research program aimed at extending the atmospheric measurements of Hess and of Werner Kolhörster (1881-1945), who, in 1914, undertook a flight to $9300 \mathrm{~m}$. Millikan and Bowen (1926) had found it difficult to keep their instruments working at the cold temperatures encountered at high altitudes, and Regener overcame this problem by enclosing his equipment in a light gondola encased in cellophane. The cellophane turned the gondola into an effective greenhouse against the low temperatures, and the apparatus was operated at what was effectively room temperature. Again, Georg Pfotzer (1909-1981) has given a good description of the challenges Regener faced and the solutions that he adopted (Pfotzer, 1985).

\subsection{Results with a balloon-borne electrometer and the energy density of cosmic rays}

Between 1932 and 1934 Regener undertook several flights during which he succeeded in making measurements of the rate of ionisation up to heights in the atmosphere where the overburden was less than $50 \mathrm{~mm} \mathrm{Hg}\left(\sim 50 \mathrm{~g} \mathrm{~cm}^{-2}\right)$. The data from the first flight are shown in Fig. 2. The maximum height reached was determined by the point at which one of the three 


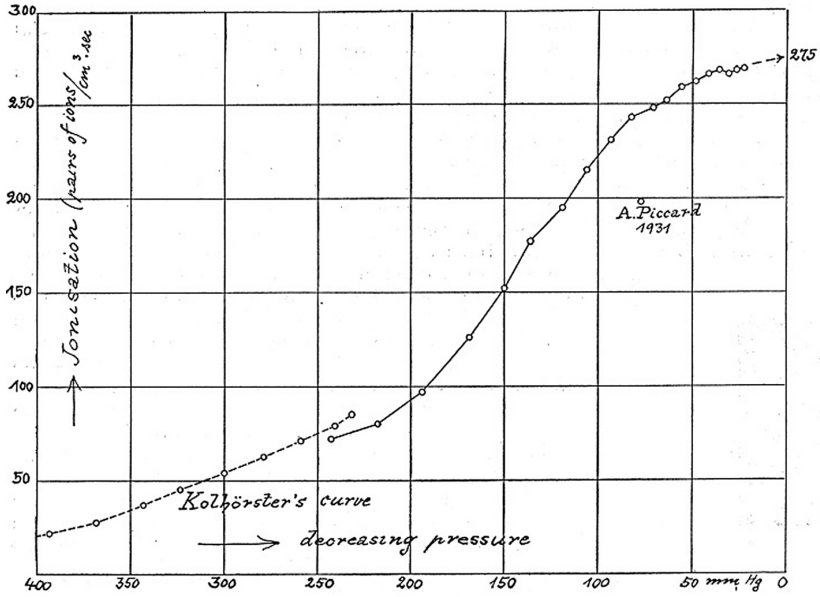

Figure 2. Ionisation data from Regener (1932) taken using an electrometer and a $2.1 \mathrm{~L}$ ionisation chamber. The ionisation rate (ion pairs $\mathrm{cm}^{-3} \mathrm{~s}^{-1}$ ) is shown as function of decreasing pressure $(\mathrm{mm} \mathrm{Hg})$. Also shown are data from Kolhörster and Piccard. The extrapolated value is shown as 275 ion pairs $\mathrm{cm}^{-3} \mathrm{~s}^{-1}$. As was customary at the time, no errors are shown on the data points. Using these data Regener was able to confirm the results of Kolhörster and infer that the rate of production of ionisation had reached a maximum value, which he extrapolated to 275 ion pairs $\mathrm{cm}^{-3} \mathrm{~s}^{-1}$. He defined this as the "intensity of the cosmic radiation" at "its entrance to the atmosphere".

or four lifting balloons burst, ozone interacting with the rubber probably being the cause of the rupture.

In a paper submitted on 31 December 1932 (Regener, 1933b) and published only 4 weeks later, Regener reported the results of integrating the ionisation as a function of height to obtain the total number of ions, produced by the absorption of cosmic rays by a column of air of $1 \mathrm{~cm}^{2}$ cross section, as $1.02 \times 10^{8}$ ion pairs, to be compared with the value of $1.28 \times 10^{7}$ ion pairs estimated by Millikan and Cameron (1928b) from a larger extrapolation. Taking $32 \mathrm{eV}$ (about $6 \%$ lower than modern measurements) as the energy needed to produce an electron-ion pair in air, he deduced that the energy reaching the earth in the form of cosmic rays was $5.2 \times 10^{-2} \mathrm{erg} \mathrm{cm}^{-2} \mathrm{~s}^{-1}$. In a later paper (Millikan et al., 1933), a value of $3.2 \times 10^{-2} \mathrm{erg} \mathrm{cm}^{-2} \mathrm{~s}^{-1}$ was derived and compared with the energy falling to the earth as starlight, $6.91 \times 10^{-3} \mathrm{erg} \mathrm{cm}^{-2} \mathrm{~s}^{-1}$. Millikan and his co-authors made no reference to Regener's paper although it had been published, in English, nearly 6 months prior to their own work being submitted.

Of course, both values for the energy flux are low as both Millikan and Regener were unaware that the bulk of the cosmic rays are charged particles. Both subscribed to the photon view, and the values are about a factor 2 lower than modern estimates. These numbers were used by Baade and Zwicky in their classic paper as evidence to support their theory

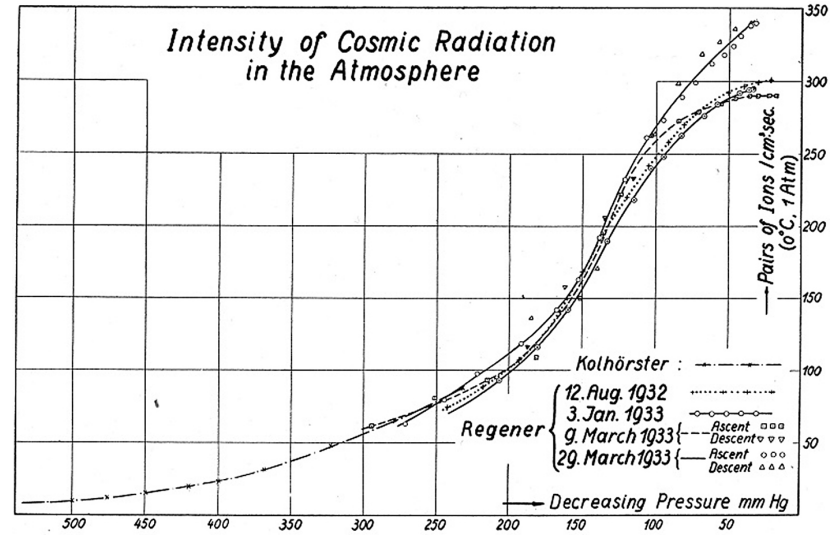

Figure 3. Ionisation data from Regener (1933c). The ionisation rate (ion pairs $\mathrm{cm}^{-3} \mathrm{~s}^{-1}$ ) is shown as function of decreasing pressure (mm Hg). Results from four flights during 1932-1933 with data corrected to one atmosphere pressure. Also shown are Kolhörster's data.

that cosmic rays were produced in supernovae (Baade and Zwicky, 1934).

From a series of balloon flights in 1932 and 1933, Regener reported the data shown in Fig. 3. The three lower curves of Fig. 3 are in good agreement, and there is evidence that the rate of production of ion pairs has reached a maximum value. It was normal practice to correct the rate of production of ion pairs to a pressure of one atmosphere: the pressures in the ionisation chamber monitored by the electrometer varied considerably over the range of three to four atmospheres in different flights.

The results from the flight of 29 March 1933 are of particular interest. The instrument was apparently working well, and no instrumental reason could be identified to account for the much higher rate of ionisation. Regener considered the possibility that radioactivity from the moon might be responsible. He rejected this as he did the possibility that "a magnetic disturbance of medium strength" that occurred on that day, while it was magnetically calm on the other days, had an influence. He noted that "it would be remarkable if there were a connexion between the magnetic intensity and the intensity of cosmic rays in the highest part of the atmosphere, and only in the highest parts: that is to say, that there are additional rays (soft rays) there perhaps coming from a sunspot". Of course, with the benefit of hindsight one might remark that the solar connection should have perhaps been given more attention, but the statement demonstrates the strong adherence that Regener, and others, had to the photon hypothesis. Indeed he discusses the shape of the curve at the highest altitudes as being evidence of an electromagnetic component.

\subsection{Discovery of the maximum}

In his 1933 Nature paper (Regener, 1933c), Regener noted that the ionisation data is for rays coming from all direc- 


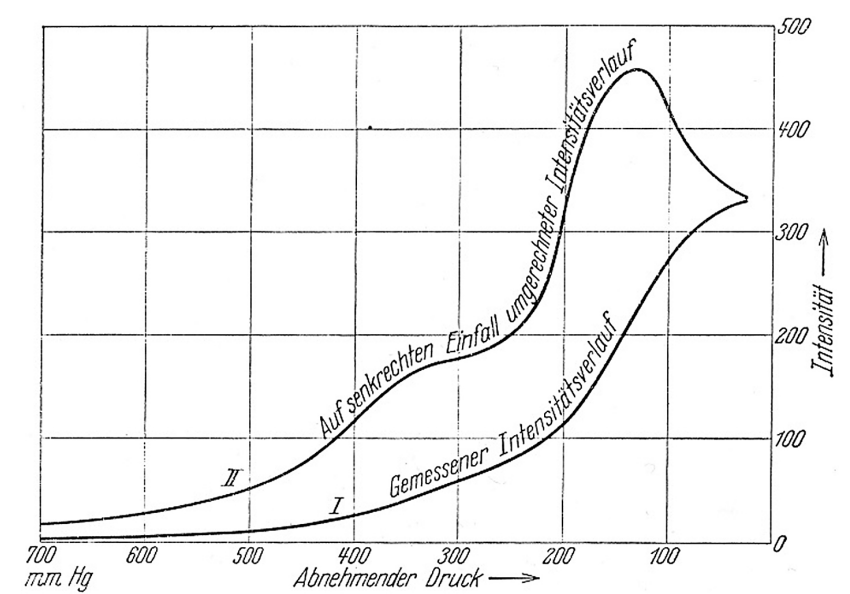

Figure 4. The ionisation rate (ion pairs $\mathrm{cm}^{-3} \mathrm{~s}^{-1}$ ) as function of decreasing pressure ( $\mathrm{mm} \mathrm{Hg}$ ) from the work of Gross (1933). Line I shows the measured rate (Regener data) for rays from all directions. Line II is the calculated rate for vertically incident rays, showing a clear maximum at about $130 \mathrm{~mm} \mathrm{Hg}$ and a shoulder at $350 \mathrm{~mm} \mathrm{Hg}$.

tions. He then went on to report that his collaborator, Bernhard Gross, had calculated the ionisation data for vertically incident rays, showing that the intensity diminished towards the top of the atmosphere, i.e. shows a maximum. In that paper (Gross, 1933), received on 6 April 1933 and published 14 June 1933, Gross acknowledges Regener for suggesting the problem and for his help with the work. The results of Gross's calculations are shown in Fig. 4.

As an excellent experimentalist, Regener wanted to exploit the Geiger-Müller (GM) tubes, developed in 1928, so that he could register single charged particles. He involved Georg Pfotzer, one of his students, in this work. Their first results, obtained with one tube carried to an altitude of $28 \mathrm{~km}$, were published in September 1934 (Regener and Pfotzer, 1934), with the ionisation measured found to be the same above $18 \mathrm{~km}$ height as reported earlier with an ionisation chamber.

A year later, in November 1935, Regener and Pfotzer described the results from two ascents with three GM tubes in coincidence, arranged to measure the vertical intensity. The solid angle was 20 degrees about the zenith (Regener and Pfotzer, 1935). Data show a clear maximum for $100 \mathrm{~mm} \mathrm{Hg}$ pressure $(\sim 16 \mathrm{~km})$ and a bump at $300 \mathrm{~mm} \mathrm{Hg}$; see Fig. 5 . Note the author ordering in these two Nature papers.

Pfotzer gives a detailed account of this work together with results from other flights in his 1936 thesis, presented on 15 May 1936 and in part published in Zeitschrift f. Physik (Pfotzer, 1936). In the acknowledgements Pfotzer thanks Regener warmly: "My sincere thanks to my idolized teacher Prof. Regener for organizing the ascents and for continuous support and help."

Pfotzer went on to have a distinguished career in physics, following Regener as Director of the Max-Planck-Institut für Stratosphärenforschung in 1956. However, it is clear to us

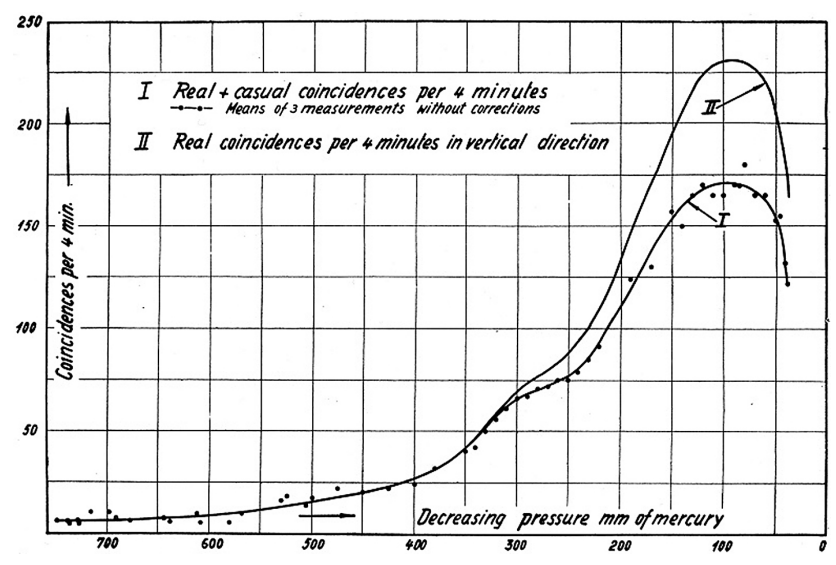

Figure 5. Data from coincidence measurements by Regener and Pfotzer (1935). The coincidence rate per $4 \mathrm{~min}$ at a solid angle of 20 degrees about the zenith is shown as function of decreasing pressure $(\mathrm{mm} \mathrm{Hg}$ ) (data points and line I). Data, corrected for deadtime losses, are shown as line II. Note the clear maximum at about $100 \mathrm{~mm} \mathrm{Hg}$.

that the real discoverer of the maximum in the rate of production of ion pairs with altitude, misleadingly called the Pfotzer maximum, was Erich Regener, with the 1935 result essentially confirming those shown in Fig. 4.

\section{Why not the Regener maximum or even the Regener-Pfotzer maximum?}

It is not at all clear why Regener's name is not now associated with the maximum in the altitude dependence of the rate of production of ion pairs. In their classic paper (Bhabha and Heitler, 1937), submitted in December 1936, Bhabha (19091966) and Heitler (1904-1981) use the work of Regener and Pfotzer, along with the Rossi transition curves (Rossi, 1938), as demonstrations of the accuracy of their theory of cosmic showers. Phrases such as "Regener's measurements of the absorption of cosmic rays in the atmosphere" are used, and in the discussion of comparisons of theory with experimental data (Sect. 7B), the title of the section is "The Regener Curve at High Altitude". Although Pfotzer's 1936 paper is in the reference list and, curiously, the order of the authors in the citation of Regener and Pfotzer (1935) has Pfotzer's name first, it is clear that Regener is seen by no less authorities than Bhabha and Heitler as the discoverer of the maximum. Heitler must surely have known what was going on in Germany, and certainly Bhabha, at that time working in Cambridge in Rutherford's laboratory, will have been aware of the close links of Rutherford and Blackett to Regener (Carmichael, 1985). In a paper written in 1938, Rossi (1938) speaks of the Regener-Pfotzer curve at $100 \mathrm{~g} \mathrm{~cm}^{-2}$ : no citation is given. However, in 1941, Schein, Jess and Wollan (Schein et al., 1941) showed a plot of the ionisation as a function of altitude in which the maximum is labelled "the 
Pfotzer maximum". In this paper, and many subsequent papers, the maximum is generally and, we contend, misleadingly referred to as the Pfotzer maximum, without citation.

It is our speculation that Regener advised Pfotzer against joint authorship as, by 1936, his difficulties with the National Socialist Party were increasing. A fascinating account of these difficulties, based on letters between her parents, has been given by the daughter of one of Regener's students (B. Hoerlin, 2011). In 1933, during the period of book burning in Germany, Regener, along with the Jewish librarian in Stuttgart, were rumoured to be targets of angry students supportive of the National Socialists. Accordingly, Hermann Hoerlin appointed himself as guardian of Regener and his family and, armed with a wooden ice axe, slept on the floor behind the door of Regener's apartment. Bettina Hoerlin also notes that Regener was one of 75 established physicists (including Heisenberg) who, in October 1936, sent a petition to the Reich's Minister of Education warning of the declining state of German physics. She remarks that "the contrarian act of signing the petition" - along with the issue of his wife - "sealed Regener's removal from the Stuttgart Faculty".
Regener was nominated by Schrödinger for the Nobel Prize in Physics in 1938 for his detailed measurements of ionisation rates, both in the atmosphere and deep under water.

It is our firm conclusion that the atmospheric and cosmic ray communities should start talking and writing about the Regener-Pfotzer maximum, or even simply the Regener maximum, when discussing the position in the atmosphere at which the rate of production of ionisation becomes a maximum. 
Appendix A: Regener's influence through his relations, students and other contacts

In addition to the work which Regener led himself, he had significant - but little recognised - influence on cosmic ray research in a number of areas. His student Hermann Hoerlin, a keen climber, with support from the Deutscher und Östereichischer Alpverein, made measurements of cosmic ray ionisation in the Peruvian Andes at altitudes up to $6100 \mathrm{~m}$. On the outward and return voyages he was able to make extensive measurements of the cosmic ray intensity as a function of latitude. Data taken on the homeward voyage from the Straits of Magellan to Hamburg form a remarkable record (Hoerlin, 1933) and confirmed the results of Clay and Berlage (1932) and of Compton (1933), obtained only slightly earlier: Hoerlin's work preceded that of Millikan. Hoerlin, too, married a woman with Jewish ancestry, and they emigrated to the United States in 1938. There, Hoerlin continued working for AGFA, the German manufacturers of photographic material and equipment with whom he had found a job in Germany after completing his $\mathrm{PhD}$. In 1953, with the encouragement of Hans Bethe, he moved to Los Alamos, where he headed the Nuclear Weapons Effects group. After the war, he studied the fluorescence emission from nuclear explosions (Hoerlin, 1963) and was regarded as one of the world's experts on high-altitude nuclear detonations (Bethe et al., 1984). This method of explosion monitoring was an idea of Teller's (Mead, 1963) and may have been an inspiration for Greisen's proposal of the fluorescence technique for the observation of the highest-energy cosmic rays. Hoerlin was deeply devoted to Regener, as an example cited in Section 3 of the main text illustrates.

Regener's son, Victor (1913-2006), emigrated to the United States before the start of World War II to work with Compton in Chicago. He moved to the University of New Mexico in Albuquerque and established a well-known cosmic ray group there (Swinson, 1995), dedicated to the study of the time variations of low-energy cosmic rays. He had made an early foray into cosmic ray work when he accompanied Hoerlin on an expedition to the Jungfraujoch in 1933, while, with his father, he studied ozone at high altitudes (Regener and Regener, 1934). Victor Regener had a strong interest in statistics and was one of the first physicists to address the question of how to assign uncertainties to small samples in a paper entitled Statistical Significance of Small Samples of Cosmic Ray Count (Regener, 1951). Later, with his son, Eric, a mathematician and a musician, Victor Regener developed a mathematical analysis of importance in establishing correlations between interplanetary magnetic-field parameters and cosmic ray diurnal variations as measured with underground data (Regener and Regener, 1970).
In 1932 Regener's daughter, Erika, married one of his research students, Henri Rathgeber. Rathgeber completed his undergraduate work and doctoral work at the University of Stuttgart. The Rathgebers emigrated to Australia in 1938, where he was employed first in Melbourne on munitions work during World War II and later at the University of Melbourne, where he studied cosmic rays. In 1952 he moved to Sydney, working on cosmic rays with $\mathrm{H}$. Messel and later with C. B. A. McCusker. With McCusker he developed a technique to study the structure of the cores of extensive air showers using large areas of liquid scintillator and image intensifiers (McCusker, Winn and Rathgeber, 1963). Rathgeber's son, Michael, was very skilled at electronics and played an important role in McCusker's air shower work until his early death in 1969. A scholarship was established at the University of Sydney by his parents in his name in 1971.

Erich Regener was highly regarded by both Rutherford and Blackett. Blackett wrote his obituary (Blackett, 1959), and Rutherford sent one of his students, H. Carmichael, to Stuttgart to be trained by Regener in the art of flying balloons. Carmichael has given an interesting account of this visit (Carmichael, 1985), which took place before an observing campaign that he made with Dymond to Baffin Island on the Wordie Expedition in 1937 (Carmichael and Dymond, 1938). 
Author contributions. The authors have contributed equally to the writing of this paper.

Acknowledgements. A. A. Watson would like to thank Virginia Trimble for pointing out the use of Regener's data on the energy density of cosmic rays by Baade and Zwicky. We are grateful to Derek Swinson for drawing our attention to his 1995 paper.

Edited by: K. Schlegel

Reviewed by: M. Witte, K. L. Aplin, and one anonymous referee

\section{References}

Alvarez, L. and Compton, A. H.: A Positively Charged Component of the Cosmic Rays, Phys. Rev., 43, 835-836, 1933.

Baade, W. and Zwicky, F.: Cosmic Rays from Super-Novae, P. Natl. Acad. USA, 20, 259-263, 1934.

Bethe, H. A., Kerr, D. M., and Jeffries, R. A.: Obituary H. W. Hoerlin, Phys. Today, 82-83, 1984.

Bhabha, H. J. and Heitler, W.: The Passage of fast Electrons and the Theory of Cosmic Showers, Proc. Roy. Soc. A, 159, 432-458, 1937.

Blackett, P. M. S.: Obituary: Erich Regener, Nature, 175, 11071108, 1959.

Carmichael, H.: Edinburgh, Cambridge, and Baffin Bay, edited by: Sekido, Y. and Elliot, H., Early History of Cosmic Ray studies, D. Reidel 1985, 99-113, 1985.

Carmichael, H. and Dymond, E. G.: High-Altitude Cosmic Radiation Measurements near the Magnetic Axis-Pole, Nature 141, 910-911, 1938.

Clay, J. and Berlage, H. P.: Variation der Ultrastrahlung mit der geographischen Breite und den Erdmagnetismus (in German), Naturwiss., 20, 687-688, 1932.

Compton, A. H.: A Geographic Study of Cosmic Rays. Phys. Rev. 43, 387-403, 1933.

Geiger, H.: Lord Rutherford, Regener, E. et al. Discussion on UltraPenetrating Rays, Proc. Roy. Soc. A, 132, 331-352, 1931.

Greisen, K.: Highlights in Air Shower Studies, 1965. Proceedings of the 9th International Conference on Cosmic Rays, Inst. Phys., 2, 609-615, 1966.

Gross, B.: Zur Absorption der Ultrastrahlung (in German), Zeit. Phys., 83, 214-221, 1933.

Hess, V. F.: Über Beobachtungen der durchdringenden Strahlung bei sieben Freiballonfahrthen. Phys. Zeits., 13, 1084-1091 (In German: On the observation of the penetrating radiation from seven balloon flights), 1912.

Hoerlin, B.: "Steps of Courage" My Parents' Journey from Nazi Germany to America, p. 49 and p. 130, USA, 2011.

Hoerlin, H.: Latitude Effect of Cosmic Radiation, Nature, 132, 6161, 1933.

Hoerlin, H.: Air Fluorescence Excited by High Altitude Nuclear Explosions. Los Alamos Report, LA-3417-MS, 1-74, 1963.

Johnson, T. H.: The Azimuthal Asymmetry of the Cosmic Radiation, Phys. Rev., 43, 834-835, 1933.
Kolhörster, W.: Messungen der durchdringenden Stralungen bis in Höhen von $9300 \mathrm{~m}$ (In German), Verh. deutsche phys. Gesellschaft, 16, 719-721, 1914.

McCusker, C. B. A., Winn, M. M., and Rathgeber, H. D.: Two Large Air Shower Experiments, Proceedings of 8th International Conference on Cosmic Rays, Jaipur, 4 pp., 306-309, 1963.

Mead, J. B.: Properties of Teller Light (Air Fluorescence) induced by $22 \mathrm{MeV}$ electrons, CRD Sigma 3, UCRL-7604, Lawrence Radiation Laboratory, 1963.

Millikan, R. A. and Bowen, I. S.: High Frequency Rays of Cosmic Origin I. Sounding Balloon Observations of Extreme Altitudes, Phys. Rev., 27, 353-361, 1926.

Millikan, R. A. and Cameron, G. H.: New Results on Cosmic Rays, Nature, 121, 19-26, 1928a.

Millikan, R. A. and Cameron, G. H.: New Precision in Cosmic Ray Measurements; Yielding Extension of Spectrum and Indications of Bands, Phys. Rev., 31, 921-930, 1928b.

Millikan, R. A., Bowen, I. S., and Neher, H. V.: New High-Altitude Study of Cosmic-Ray Bands and a new Determination of Their Energy Content, Phys. Rev., 44, 246-252, 1933.

Paetzold, H. K., Pfotzer, G., and Schopper, E.: Erich Regener als Wegbereiter der extraterrestrischen Physik, edited by: Birett, H., Helbig, K., Kertz, W., and Schmucker, U., in: Zur Geschichte der Geophysik, Springer Berlin, 167-188, 1974.

Pfotzer, G.: Dreifachkoinzidenzen der Ultrastrahlung aus vertikaler Richtung in der Stratosphäre (in German), Zeit. Phys. 102, 2358, 1936.

Pfotzer, G.: On Erich Regener's cosmic-ray work in Stuttgart and related subjects, edited by: Sekido, Y. and Elliot, H., edited by: Early History of Cosmic Ray Studies, D. Reidel, 75-89, 1985.

Regener, E.: Über die chemische Wirkung kurzwelliger Strahlung auf gasförmige Körper (In German), thesis univ. Berlin, 1905.

Regener, E.: Über Ladungsbestimmungen an Nebelteilchen, Phys. Zeit., 12, 135-141, 1911.

Regener, E.: Über neuere Versuche über die sogennante durchdringende Höhenstrahlung in der Erdatmosphäre (in German), Naturwissentschaftlige Monatshefte 25, 240, 1928.

Regener, E.: Spectrum of Cosmic Rays, Nature 127, 233-234, 1931.

Regener, E.: Intensity of Cosmic Radiation in the High Atmosphere, Nature 130, 364-364, 1932.

Regener, E.: Die Absorptionskurve der Ultrastrahlung und ihre Deutung (in German), Phys. Z., 34, 306-323, 1933a.

Regener, E.: Energy of Cosmic Rays. Nature, 131, 130-130, 1933b.

Regener, E.: New Results in Cosmic Ray Measurements, Nature, 132, 696-698 1933c.

Regener, E. and Regener, V. H.: Aufnahme der ultravioletten Sonnenspektrums in der Stratosphäre und vertikale Ozonverteilung (in German), Phys. Zeit. 35, 788-793, 1934.

Regener, E. and Pfotzer, G.: Messungen der Ultrastrahlung in der oberen Atmosphäre mit dem Zählrohr (in German), Phys. Zeit. 35, 779-784, 1934.

Regener, E. and Pfotzer, G.: Intensity of the Cosmic Ultra-Radiation in the Stratosphere with the Tube-Counter, Nature, 134, 325325, 1935.

Regener, E. and Pfotzer, G.: Vertical Intensity of Cosmic Rays by Threefold Coincidences in the Stratosphere, Nature, 136, 718719, 1935 .

Regener, V. H.: Statistical Significance of Small Samples of Cosmic-Ray Counts, Phys. Rev., 84, 161-162, 1951. 
Regener, V. H. and Regener, E.: Cosmic Rays Underground and the Interplanetary Magnetic Field, Zeitschr. f. Geophys., 40, 761766, 1970.

Rossi, B.: Über die Eigenschaften der durchdringenden Korpuskularstrahlung im Meerniveau (in German), Zeit. Phys., 82, 151$178,1933$.

Rossi, B.: Further Evidence for Radioactive Decay of Mesotrons, Nature, 142, p. 993, 1938.
Rossi, B.: Arcetri, 1928-1932, in: Early History of Cosmic Ray Studies, edited by: Sekido, Y. and Elliot, H., D. Reidel 1985, 5389, 1985.

Schein, M., Jesse, W. P., and Wollan, E. O.: The Nature of the Primary Cosmic Radiation and the Origin of the Mesotron, Phys. Rev., 59, p. 615, 1941.

Swinson, D. B.: Diurnal variations underground since 1959, Proceedings of the 24th International Cosmic Ray Conference, Rome, 4, 627-630, 1995. 